\title{
Tissue-specific deletion of Foxa2 in pancreatic $\beta$ cells results in hyperinsulinemic hypoglycemia
}

\author{
Newman J. Sund, ${ }^{1,2}$ Marko Z. Vatamaniuk, ${ }^{2,3}$ Melissa Casey, ${ }^{1,2}$ Siew-Lan Ang, ${ }^{5}$ \\ Mark A. Magnuson, ${ }^{6}$ Doris A. Stoffers, ${ }^{2,4}$ Franz M. Matschinsky, ${ }^{2,3}$ and Klaus H. Kaestner ${ }^{1,2,7}$ \\ ${ }^{1}$ Department of Genetics, ${ }^{2}$ Penn Diabetes Center, ${ }^{3}$ Department of Biochemistry and Biophysics, and ${ }^{4}$ Division of \\ Endocrinology, Diabetes, and Metabolism, Department of Medicine, University of Pennsylvania School of Medicine, \\ Philadelphia, Pennsylvania 19104, USA; ${ }^{5}$ Institut de Génétique et de Biologie Moléculaire et Cellulaire, CNRS/INSERM/ \\ Université Louis Pasteur, BP163, 67404 Illkirch cedex, CU de Strasbourg, France; ${ }^{6}$ Department of Molecular Physiology and \\ Biophysics, Vanderbilt University School of Medicine, Nashville, Tennessee 37232, USA
}

We have used conditional gene ablation to uncover a dramatic and unpredicted role for the winged-helix

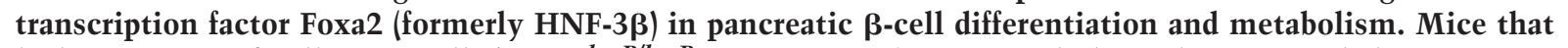
lack Foxa2 specifically in $\beta$ cells (Foxa $2^{\text {IoxP/loxP }}$; Ins.Cre mice) are severely hypoglycemic and show dysregulated insulin secretion in response to both glucose and amino acids. This inappropriate hypersecretion of insulin in the face of profound hypoglycemia mimics pathophysiological and molecular aspects of familial hyperinsulinism. We have identified the two subunits of the $\beta$-cell ATP-sensitive $K^{+}$channel $\left(K_{\mathrm{ATP}}\right)$, the most frequently mutated genes linked to familial hyperinsulinism, as novel Foxa2 targets in islets. The Foxa $2^{\text {IoxP/loxP }}$; Ins.Cre mice will serve as a unique model to investigate the regulation of insulin secretion by the $\beta$ cell and suggest the human FOXA2 as a candidate gene for familial hyperinsulinism.

[Key Words: Hepatocyte nuclear factor; persistent hyperinsulinemic hypoglycemia of infancy; familial hyperinsulinism]

Received April 5, 2001; revised version accepted May 16, 2001.

During mouse development, dorsal and ventral pancreatic primordia first appear as evaginations of the foregut endoderm at $9 \mathrm{~d}$ postcoitum (Slack 1995). The induction of the pancreatic phenotype in the dorsal pancreatic bud is dependent on a permissive signal from the adjacent notochord (Kim et al. 1997; St-Onge et al. 1999). In the mouse, the two pancreatic buds merge at $10.5 \mathrm{~d}$ postcoitum and form exocrine and endocrine compartments. The exocrine pancreas is composed of a relatively homogeneous population of acinar cells that secrete digestive enzymes. The endocrine compartment in the islets of Langerhans differentiates into four endocrine cell types, the $\alpha, \beta, \delta$, and PP cells, which express glucagon, insulin, somatostatin, and pancreatic polypeptide, respectively (Alpert et al. 1988; Slack 1995).

The winged-helix transcription factors Foxa1, Foxa2, and Foxa3 (formerly HNF3 [hepatocyte nuclear factor 3] $\alpha, \beta$, and $\gamma$; see Kaestner et al. 2000) are candidates for regulators of pancreatic development. During formation of the definite endoderm from which the pancreatic primordium is derived, Foxa2 mRNA is detected

${ }^{7}$ Corresponding author.

E-MAIL kaestner@mail.med.upenn.edu; FAX (215) 573-5892.

Article and publication are at http://www.genesdev.org/cgi/doi/10.1101/ gad. 901601 . first, followed by Foxa1 and finally Foxa3 (Ang et al. 1993; Monaghan et al. 1993; Sasaki and Hogan 1993). Gene targeting has shown that Foxa2 is required for the development of the node and visceral endoderm because these structures are missing or abnormal in embryos homozygous for a null mutation in the Foxa2 gene (Ang and Rossant 1994; Weinstein et al. 1994; Dufort et al. 1998). However, the functions of Foxa2 in pancreatic development and in $\beta$-cell physiology can not be addressed using the Foxa2 null allele, as even embryos obtained from tetraploid embryo-ES cell aggregations lack foregut endoderm (Dufort et al. 1998).

To overcome the limitations of the current genetic models, we have generated mice lacking Foxa2 specifically in pancreatic $\beta$ cells, using the Cre-loxP recombination system, and have analyzed the contribution of Foxa2 to $\beta$-cell development and physiology. Using this new model, we have uncovered a dramatic and unpredicted role for Foxa2 in $\beta$-cell function and glucose homeostasis.

\section{Results}

Generation of $\beta$ cell-specific Foxa2 knockout mice

Pancreatic $\beta$ cell-specific Foxa2 knockout mice (Foxa2 $2^{\operatorname{lox} P / \operatorname{lox} P} ;$ Ins.Cre) were generated by breeding 
Foxa $2^{\operatorname{lox} P / \operatorname{lox} P}$ homozygous mice with Ins.Cre transgenic mice, which express the Cre recombinase cDNA under the control of the $\beta$ cell-specific rat insulin 2 promoter (Kulkarni et al. 1999; Postic et al. 1999; Sund et al. 2000). The resulting Foxa2 $2^{10 x P /+}$; Ins.Cre offspring were mated to Foxa $2^{\operatorname{lox} P / \operatorname{lox} P}$ homozygotes to obtain the Foxa $2^{\operatorname{lox} P / \operatorname{lox} P}$; Ins.Cre mice and three littermate control groups: Foxa $2^{10 \times P /+}$, Foxa $2^{\operatorname{lox} P / \operatorname{lox} P}$, and Foxa2 $2^{\operatorname{lox} P /+}$; Ins.Cre. Foxa $2^{\text {loxP/lox } P}$; Ins.Cre mice were born in the expected mendelian distribution, and no significant differences in appearance or body weight were observed at birth between these mice and their control littermates (see Fig. 2b).
To assess the onset and efficiency of Cre-mediated gene deletion in Foxa $2^{\operatorname{lox} P / 10 x P}$; Ins.Cre mice, Foxa2 expression was examined in $\beta$ cells by performing immunohistochemistry using anti-insulin and anti-Foxa2 antibodies during various stages of islet ontogeny (Fig. 1af). Foxa2 is normally expressed in all islet cell types, including $\beta$ cells, and in exocrine acinar cells throughout development (Fig. 1a,c,e,g). As expected, the majority of the $\beta$ cells from 14.5 - and 16.5 d postcoitum Foxa2 ${ }^{\text {loxP/loxP }}$; Ins.Cre embryos had lost Foxa2 expression (Fig. 1b; data not shown). On postnatal day 8 (P8), Foxa2 is inactivated in $85 \%$ of the $\beta$ cells from Foxa $2^{\operatorname{lox} P / \operatorname{lox} P}$; Ins.Cre mice (Fig. 1d). By P22, Foxa2 protein is deleted in $>95 \%$ of the

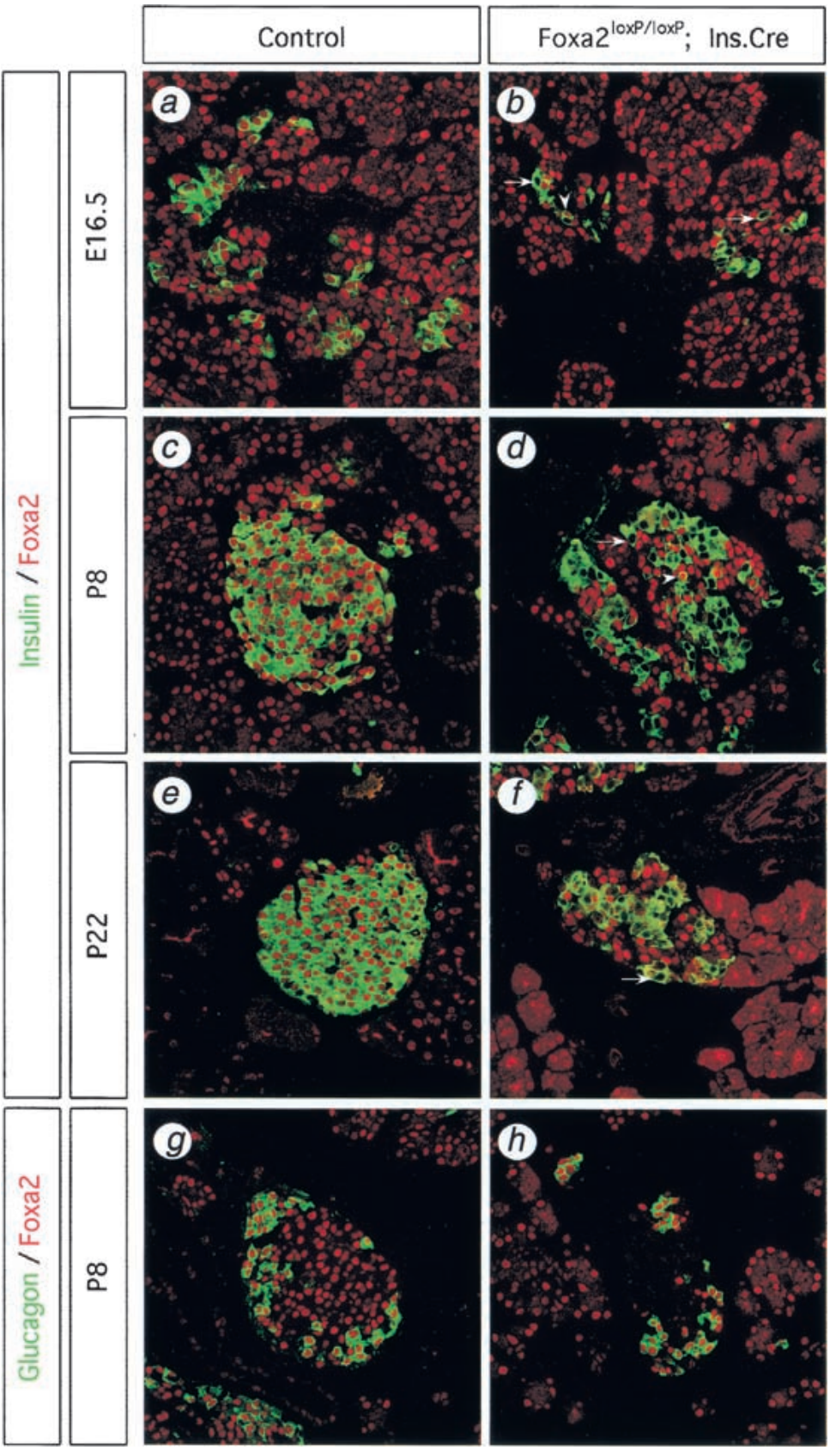

Figure 1. The Foxa $2^{10 x P}$ allele is efficiently and specifically deleted in pancreatic $\beta$ cells by the Ins.Cre transgene. Immunofluourescence analysis of pancreas sections from mice at $16.5 \mathrm{~d}$ post coitum $(a, b)$, postnatal day $8(\mathrm{P} 8 ; c, d, g, h)$, and $\mathrm{P} 22(e, f)$, double-labeled for either Foxa2 (red) and insulin (green; $a-f$ ) or Foxa2 (red) and glucagon (green; $g, h$ ). Foxa2 is normally expressed in all islet cell types, including $\beta$ cells and $\alpha$ cells, and in some acinar cells $(a, c, e, g)$. (b) Foxa2 is inactivated in $\beta$ cells as early as embryonic day 16.5 (E16.5) in Foxa2 $2^{\text {loxP/loxP }}$; Ins.Cre mice. Cre-mediated deletion of Foxa 2 occurs in $85 \%$ of $\beta$ cells in P8 mice $(d)$ and in more than $99 \%$ of $\beta$ cells in P22 mice $(f)$. Arrows $(b, d, f)$ show $\beta$ cells that have Foxa2 deleted, whereas arrowheads $(b, d)$ show $\beta$ cells in which Foxa2 protein persists. However, Foxa2 is not deleted in either $\alpha$ cells $(h)$ or acinar cells in Foxa $2^{10 x P / / 0 x P}$; Ins.Cre mice, indicating the specificity of the Ins.Cre transgene. Images were obtained at 400× magnification using fluorescent confocal microscopy of representative pancreatic sections from wild-type control (Control) mice $(a, c, e, g)$ and mutant Foxa2 $2^{\text {loxP/loxP }} ;$ Ins. Cre mice $(b, d, f, h)$. 
Sund et al.

$\beta$ cells (Fig. 1f). P22 is the latest stage of mutant mice that were available for analysis because of the severity of the phenotype (see below).

The specificity of Foxa2 deletion in our model was assessed by examining Foxa2 expression in glucagon-expressing $\alpha$ cells, in exocrine acinar cells, and in hepatocytes from P8 Foxa $2^{\operatorname{lox} P / \operatorname{lox} P}$; Ins.Cre mutant mice. In contrast to the situation in pancreatic $\beta$ cells, Foxa2 expression was maintained in all pancreatic $\alpha$ cells and acinar cells, as well as in all hepatocytes (Fig. 1g; hepatocyte data not shown). Our observations are consistent with Cre immunostaining in Ins.Cre mice in which Cre recombinase was expressed in $82 \%$ of the $\beta$ cells but was not ectopically expressed in other islet cell types or in acinar cells (Postic et al. 1999). In summary, we conclude that Foxa2 is efficiently and specifically deleted in up to $95 \%$ of $\beta$ cells in Foxa2 $2^{\operatorname{lox} P / 10 x P}$; Ins.Cre mice, with de- letion initiated during early islet differentiation and continuing in mature islets.

\section{$\beta$ Cell-specific deletion of Foxa2 results in postnatal death caused by severe persistent hyperinsulinemic hypoglycemia}

To determine the role of Foxa2 in pancreatic $\beta$-cell differentiation and function, we examined offspring from crosses of double heterozygous Foxa $2^{10 x P /+}$; Ins. Cre mice mated to Foxa2 $2^{\operatorname{lox} P / \operatorname{lox} P}$ homozygous mice. At birth, Foxa $2^{\operatorname{lox} P / \operatorname{lox} P}$; Ins. Cre mice were indistinguishable from control littermates by appearance and birth weight (Fig. 2b). However, mutant mice quickly became growth-retarded and usually died between P9 and P12 (Fig. 2a,b). Of $>300$ offspring analyzed from this mating to date, no mutant mouse that lacks Foxa2 in $\beta$ cells has ever sur-
Figure 2. Foxa $2^{10 \times P / 10 x P}$; Ins.Cre mice are growth-retarded and die shortly after birth because of severe hyperinsulinemic hypoglycemia. (a) Eight-day-old (P8) Foxa2 $2^{\text {loxP/loxP }}$; Ins.Cre mutant mouse $(\mathrm{M}$; top) and a control littermate (WT; bottom) from a typical litter between Foxa2 $2^{10 x P /+}$; Ins.Cre and Foxa2 $2^{\text {loxP/loxP }}$ mice on a mixed outbred-CD1 background. $(b)$ Growth curve for a litter obtained from mating Foxa $2^{\text {loxP/+ }}$; Ins.Cre and Foxa $2^{\text {loxP/loxP }}$ mice. Foxa $2^{10 \times P / 10 x P}$; Ins.Cre mutant mice (filled diamond) are growth retarded relative to control littermates (open square). Between P9 and P12, Foxa2 $2^{10 x P / 10 x P}$; Ins.Cre mutant mice lose weight rapidly, and most die with severe hypoglycemia. Values are means \pm SEM of $n=5$ mice. $(c-$ $e, h)$ Offspring from matings between $\mathrm{Foxa}^{\mathrm{loxP} /{ }^{\circ}}$; Ins.Cre and Foxa $2^{\text {loxP/loxP }}$ mice were killed on P8 and blood glucose $(c)$, plasma insulin $(d)$, plasma glucagon $(e)$, and plasma nonesterified (NE) fatty acid (h) concentrations were determined as described in Materials and Methods. Each bar represents the mean \pm SEM, with the number indicated in parenthesis. ${ }^{\star}{ }^{\star}, P<0.005$; Foxa2 $2^{\operatorname{lox} P / \operatorname{lox} P}$; Ins.Cre (cross-hatched bars) vs. Foxa2 $2^{10 x P /+}$ (stippled bars) or Foxa2 loxP/loxP (horizontal-striped bars) or Foxa $2^{10 \times P /+}$; Ins.Cre (hatched bars). $(f)$ The insulin to glucagon ratio was determined by dividing mean plasma insulin concentrations $(d)$ by mean plasma glucagon concentrations $(e)$. $(g)$ Liver glycogen content was determined in P8 Foxa $2^{\text {loxP/loxP }}$; Ins.Cre mutant mice (cross-hatched bars) and control littermates (unfilled bars). Each bar represents the mean $\pm S E M$, with the number indicated in parenthesis. ${ }^{\star \star}, P<0.005$; Foxa $2^{\text {loxP/loxP }}$; Ins.Cre vs. all control littermates. a
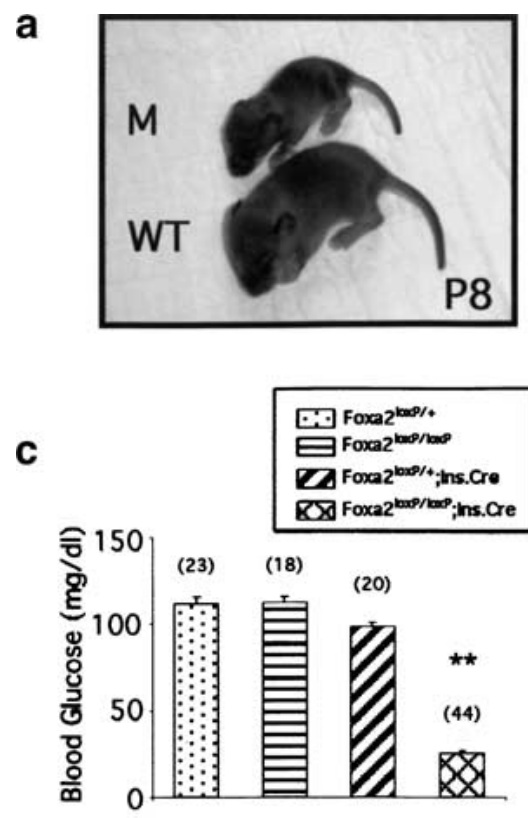

e

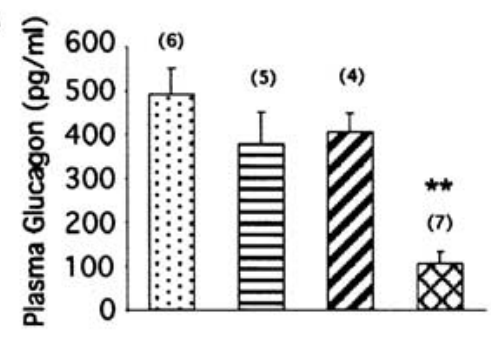

g

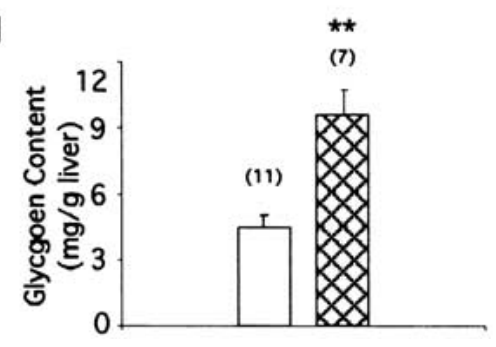

b

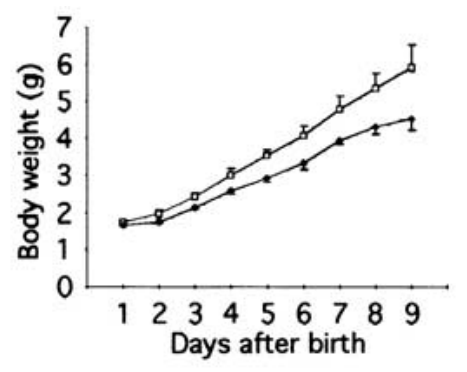

d

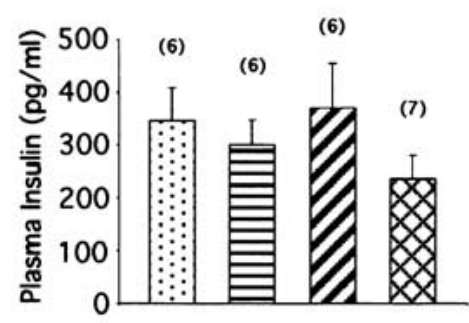

f

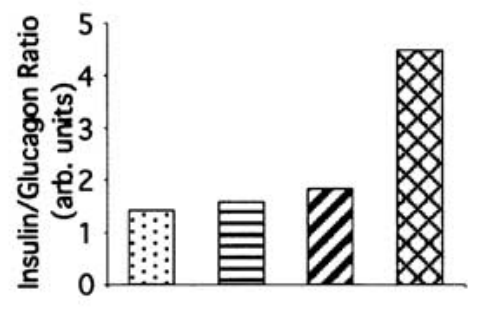

h

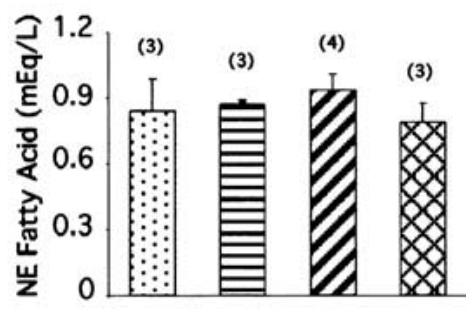


vived to weaning. The mutant mice showed signs of metabolic dysfunction, including seizure activity, suggesting severe hypoglycemia. Blood glucose levels were indeed found to be extremely low in the mutant mice (Fig. 2c). As the ratio of insulin to glucagon is critical in maintaining euglycemia, we determined the plasma levels of these hormones in P8 Foxa $2^{\operatorname{lox} P / \operatorname{lox} P}$; Ins.Cre mice and their littermate controls. Plasma insulin levels in mutant mice were similar to their euglycemic control littermates (Fig. 2d). The plasma insulin levels in the mutant mice are inappropriately high considering the severe hypoglycemia in these animals. In addition, plasma glucagon levels in Foxa $2^{\operatorname{lox} P / \operatorname{lox} P}$; Ins.Cre mice were five-fold lower than in control littermates (Fig. 2e). Thus, Foxa2 $2^{\text {loxP/loxP }}$; Ins.Cre mice have an approximately three- to fourfold increase in their insulin to glucagon ratio compared with that of wild-type controls, which accounts for their severe hypoglycemia (Fig. 2f).

The abnormal hormone levels observed in the Foxa $2^{\operatorname{lox} P / \operatorname{lox} P}$; Ins.Cre mice are expected to also affect other aspects of metabolism, in particular the storage of glucose as glycogen and the levels of free fatty acids in the blood. In the normal response to low blood glucose levels, changes in pancreatic hormones effect glycogen breakdown in skeletal muscle and liver. In contrast, livers from P8 Foxa2 $2^{\text {loxP/loxP }}$; Ins.Cre mice had 2.5 -fold higher glycogen content than their control littermates, which is consistent with the observed hyperinsulinemia in these mice (Fig. 2g). Another physiological response to hypoglycemia is the mobilization of free fatty acids from triglyceride stores. However, there was no significant change in nonesterified fatty acid levels in plasma from mutant mice compared with littermate controls (Fig. 2h). This lack of an increase in free fatty acids during severe hypoglycemia is another reflection of the hyperinsulinemia in these mutant mice. Taken together, mice deficient for Foxa2 in the pancreatic $\beta$ cells die shortly after birth because of hyperinsulinemic hypoglycemia despite having abundant hepatic glycogen stores.

\section{Foxa2 in the $\beta$ cell impacts on islet architecture but not cell lineage allocation}

Several mechanisms could account for the observed relative increase in circulating insulin in Foxa $2^{\operatorname{lox} P / \operatorname{lox} P}$; Ins.Cre mice, including changes in islet cell lineage allocation, abnormalities in insulin biosynthetic rates, defective regulation of insulin secretion, or a combination of these factors. Similar possibilities could also explain the decrease in circulating glucagon levels. Lack of Foxa2 in $\beta$ cells could, for instance, result in an increase in insulin-producing $\beta$ cells at the expense of the glucagonproducing $\alpha$ cells. This possibility is relevant in light of recent gene-targeting experiments of other transcription factors expressed in the pancreas, including Pax6 and $P a x 4$, in which null mutants lacked pancreatic $\alpha$ or $\beta$ cells, respectively (Sosa-Pineda et al. 1997; St-Onge et al. 1997).
Islet composition was assessed first qualitatively by immunostaining with markers for $\alpha, \beta$, and $\delta$ cells (Fig. 3). $\beta$ Cells, the predominant cell type in islets, form the core of the normal islet, whereas the less abundant $\alpha$ and $\delta$ cells are distributed in the islet periphery. $\beta$ Cells, $\alpha$ cells, and $\delta$ cells were all present in Foxa2 $2^{\operatorname{lox} P / \operatorname{lox} P}$; Ins.Cre islets. However, in contrast to the roughly spherical islets seen in wild-type mice, islets from mutant mice were irregularly formed and appeared to be composed of multiple lobules. Furthermore, mutant islets had a strikingly disorganized architecture with non- $\beta$ cells intermingled in the islet core. However, all islet cell types were present in the mutant mice, with no evidence for inappropriate coexpression of islet hormones.

To assess islet composition quantitatively, we determined $\alpha$ - and $\beta$-cell area in Foxa $2^{\text {loxP/loxP }}$; Ins.Cre mice and control littermates. As shown in Figure $4 \mathrm{a}, \beta$-cell area was modestly decreased by $32 \%$ in Foxa $2^{\text {loxP/loxP }}$; Ins.Cre pancreata when compared with that of control littermates, whereas $\alpha$-cell area was unaffected (Fig. 4b). Thus, $\beta$ cells from Foxa2 $2^{\operatorname{lox} P / l o x P}$; Ins.Cre islets appeared to differentiate normally, expressing appropriate cell lineage markers with a modest reduction in $\beta$-cell area. Therefore, our results strongly indicate that changes in cell lineage allocation are not responsible for the ob-

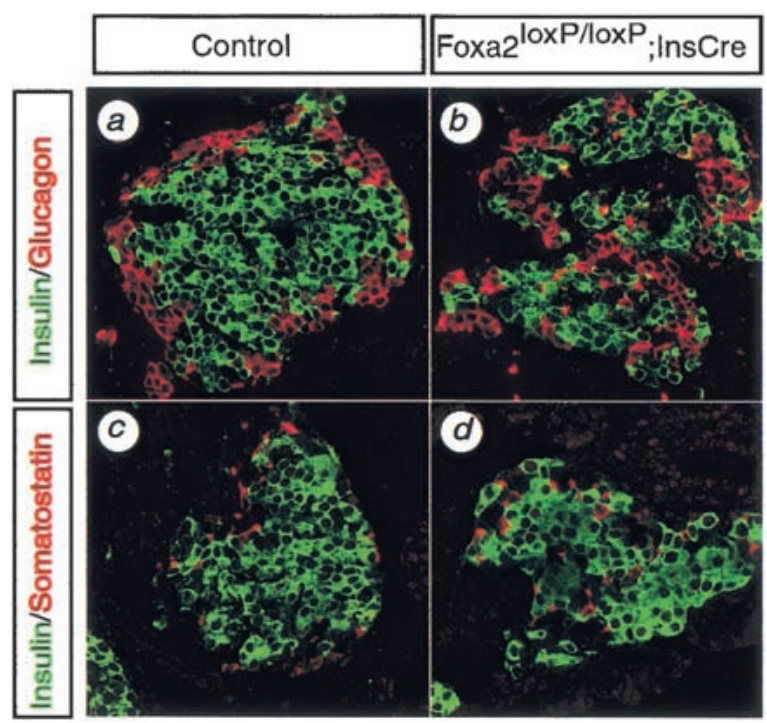

Figure 3. Foxa $2^{\text {loxp/loxP }}$; Ins.Cre mice show perturbed islet architecture, but islet cell markers are expressed normally. Pancreatic sections from control $(a, c)$ and Foxa2 $2^{\operatorname{loxP} / \text { loxP }}$; Ins.Cre $(b, d)$ mice were immunostained for two different islet cell lineage markers, and images were captured by confocal microscopy. The markers were insulin for $\beta$ cells $(a-d)$, glucagon for $\alpha$ cells $(a, b)$, and somatostatin for $\delta$ cells $(c, d)$. $\beta$ Cells normally form the core of the islet with non- $\beta$ cells positioned on the periphery of the islet, as seen in control mice $(a, c)$. In contrast, islets from Foxa2 ${ }^{\text {loxP/loxP }}$; Ins. Cre mice have non- $\beta$ cells intermingled in the core of the islet, known as a mixed islet phenotype $(b, d)$. Insulin is not co-expressed with either the $\alpha$-cell marker $(a, b)$ or the $\delta$-cell marker $(c, d)$ in control or Foxa $2^{\text {loxP/loxP }}$; Ins.Cre islets. Magnification, 400x. 
a

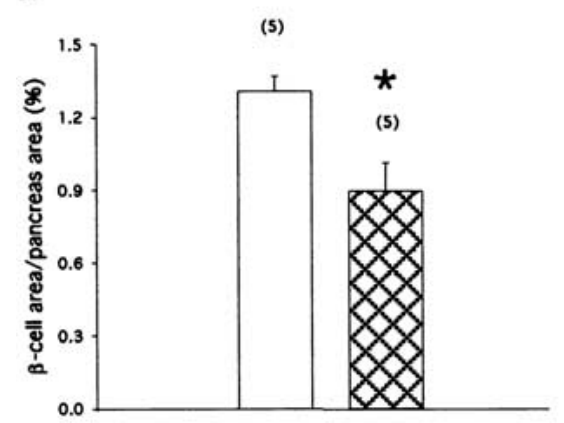

d

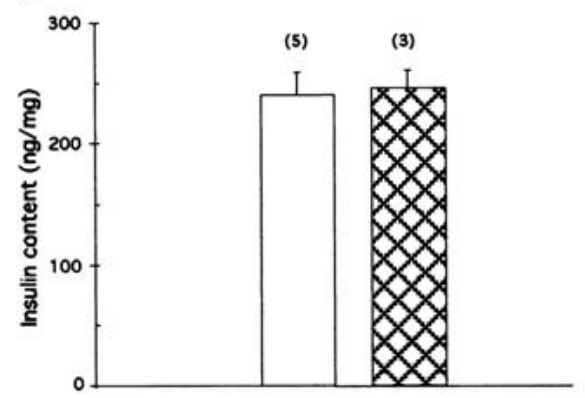

b
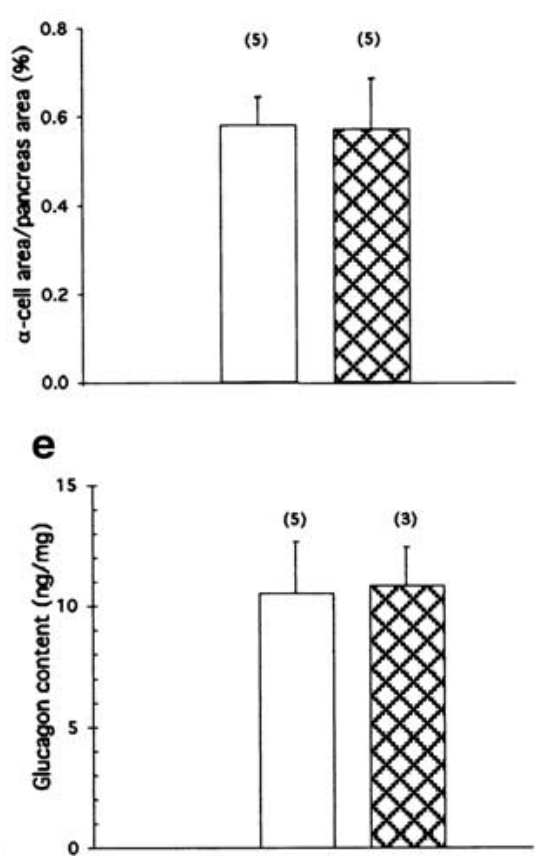

C

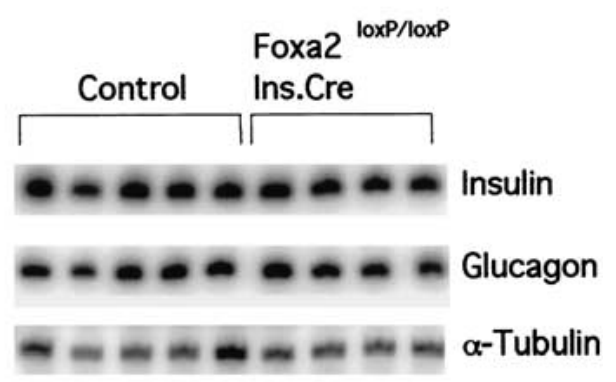

Figure 4. Quantitative analysis of islet cell area and biosynthesis of insulin and glucagon in Foxa $2^{\text {loxP/loxP }}$; Ins.Cre mice. $(a, b)$ Pancreatic sections from eight-day-old control (P8; unfilled bars) and Foxa $2^{\text {loxP/loxP }}$; Ins.Cre (Mutant, cross-hatched bars) mice were immunostained for both insulin and glucagon to determine $\beta$-cell area $(a)$ and $\alpha$-cell area $(b)$, respectively, which were normalized to total pancreatic area (pancreas area). Bars represent means \pm SEM, with number indicated in parenthesis. ${ }^{\star}, P<0.05$; Foxa2 $2^{\operatorname{lox} P / \operatorname{lox} P}$; Ins.Cre vs. control mice. $(c)$ Reverse-transcription analysis of total RNA isolated from whole pancreata of P8 control and Foxa2 $2^{\text {loxP/loxP }} ;$ Ins.Cre mice. No significant differences between control and mutant mice in insulin 1 (Insulin) or glucagon steady-state mRNA levels were detected when quantified using phosphorImager analysis (data not shown). $\alpha$-Tubulin served as a loading control. $(d, \mathrm{e})$ Pancreatic insulin $(d)$ and glucagon content $(e)$ were measured in acid-ethanol extracts from P8 control (unfilled bars) and Foxa2 ${ }^{\operatorname{lox} P / \operatorname{lox} P} ;$ Ins. Cre (Mutant, cross-hatched bars) mice by RIA. Bars represent values \pm SEM, with number indicated in parenthesis.

served hyperinsulinemia and hypoglucagonemia in $\beta$-cell Foxa2 knockout mice.

Hormone secretion, but not biosynthesis, is regulated by Foxa2 in the $\beta$ cell

In theory, an overproduction of insulin might explain why Foxa $2^{\operatorname{lox} P / / 0 x P}$; Ins.Cre mice are hyperinsulinemic. Likewise, defective islet glucagon biosynthesis could result in decreased glucagon levels in the plasma, as observed in mice with a targeted inactivation of Foxa1 (HNF3 $\alpha)$, which show a reduction in glucagon mRNA in the pancreas (Kaestner et al. 1999; Shih et al. 1999). However, neither insulin nor glucagon mRNA levels were affected by the lack of Foxa2 in the pancreatic $\beta$ cell (Fig. 4c). Similarly, there was no difference in total insulin and glucagon content in whole pancreatic extracts from mutant and control mice (Fig. 4d,e). These results indicate that the hyperinsulinemia and hypoglucagonemia observed in Foxa $2^{\operatorname{lox} P / / \operatorname{lox} P}$; Ins.Cre mice are not the result of increased insulin, diminished glucagon biosynthesis, or both.

In light of these findings, abnormal insulin and possibly glucagon secretion seemed the most likely cause for the phenotype observed in the Foxa $2^{\text {loxP/loxP }}$; Ins.Cre mice. Glucose-stimulated insulin secretion physiologically links blood glucose levels and $\beta$-cell metabolism to release insulin into the bloodstream (Dunne and Pe- tersen 1991). Glucose enters the $\beta$ cell through GLUT2, the high $\mathrm{K}_{\mathrm{m}}$ glucose transporter in $\beta$ cells, where it is phosphorylated by glucokinase, the $\beta$-cell glucose sensor. Subsequently, glucose metabolism results in the elevation of the ATP/ADP ratio, which closes ATP-sensitive potassium $\left(\mathrm{K}_{\mathrm{ATP}}\right)$ channels in the plasma membrane. Closure of the $\mathrm{K}_{\mathrm{ATP}}$ channels causes depolarization of the plasma membrane, which activates voltage-gated calcium channels. Influx of intracellular calcium results in exocytosis of stored insulin granules and release of insulin into the bloodstream.

To test our hypothesis that abnormal insulin secretion is the cause for the hyperinsulinemic hypoglycemia in Foxa $2^{\text {loxP/loxP }}$; Ins.Cre mice, we performed in vitro perifusion assays of minced pancreas. This technique allows for the determination of pancreatic insulin and glucagon output under defined conditions. To determine the threshold for insulin secretion, we performed glucose ramp experiments using control and Foxa2loxP/loxP; Ins.Cre pancreata. As is shown in Figure 5a, control mice secreted insulin starting at a concentration of $6.5 \mathrm{mM}$ (117 mg/dL) glucose, with maximal output levels reached at $8.5 \mathrm{mM}(153 \mathrm{mg} / \mathrm{dL})$ glucose. In contrast, the Foxa2 $2^{\text {loxP/loxP }}$; Ins.Cre mice secrete insulin at a reduced glucose concentration of $4.5 \mathrm{mM}(81 \mathrm{mg} / \mathrm{dL})$ glucose, peaking at $6.5 \mathrm{mM}$ glucose, indicating a hypersensitivity to glucose stimulation. Even more striking was the failure of the mutant islets to terminate insulin secretion 
A
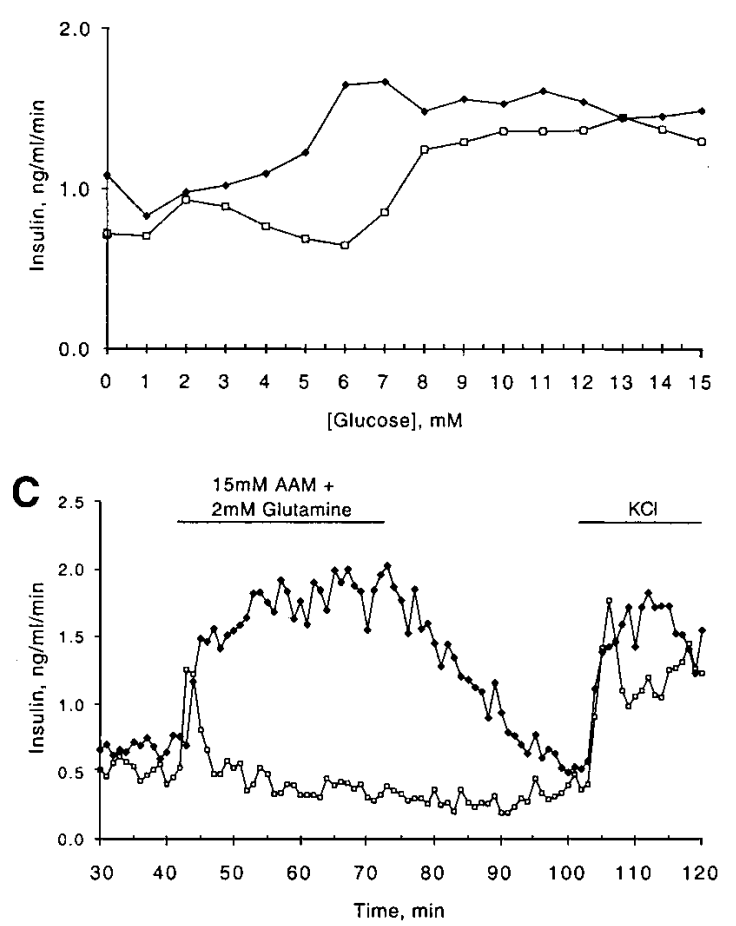

B

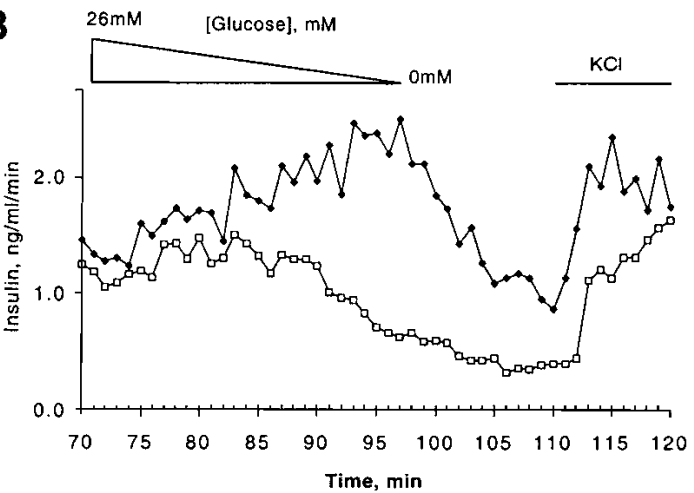

D

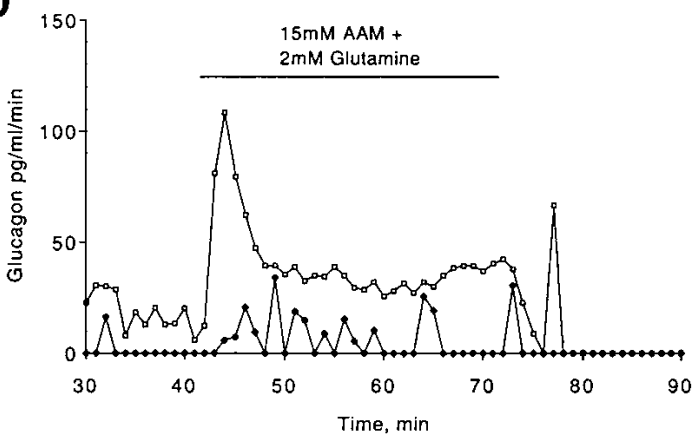

Figure 5. Regulation of hormone secretion is defective in Foxa $2^{\text {loxP/loxP }}$; Ins.Cre mice. All perifusion studies were performed at least three times and representative trace is shown for each experiment. (a) Pancreata from two postnatal day 8 (P8) controls (open squares) and Foxa2 ${ }^{\operatorname{lox} P / \operatorname{lox} P}$; Ins.Cre (Mutant, filled diamonds) mice were perifused as described in Materials and Methods with increasing concentrations of glucose from 0 to $15 \mathrm{mM}$ glucose at a rate of $1 \mathrm{mM}$ per minute. Fractions were taken every minute, and the insulin concentration was determined by RIA. (b) Continuation of experiment in $a$ with a glucose ramp decreasing from 26 to $0 \mathrm{mM}$ glucose, changing the glucose concentration at a rate of $1 \mathrm{mM}$ per minute (represented by triangle). At the end of the experiment, $15 \mathrm{mM}$ potassium chloride $(\mathrm{KCl})$ was added to the perifusate, represented by the bar. Fractions were taken every minute, and insulin concentrations were determined by RIA. $(c, d)$ Pancreata from two P8 control (open squares) and Foxa $2^{\text {loxP } / / \operatorname{lox}^{P}}$; Ins. Cre (filled diamonds) mice were perifused as described in Experimental Procedures with addition of secretagogue, $15 \mathrm{mM}$ amino acid mixture (AAM) plus $2 \mathrm{mM}$ glutamine or $15 \mathrm{mM} \mathrm{KCl}(\mathrm{KCl})$ as indicated. Fractions were taken every minute, and insulin $(c)$ and glucagon $(d)$ concentrations were determined by RIA. $c$ and $d$ represent hormone concentrations of fractions from the same perifusion experiment.

when glucose was ramped down from $26 \mathrm{mM}(468 \mathrm{mg} /$ dL) to $0 \mathrm{mM}$ (Fig. $5 \mathrm{~b}$ ), again indicating the abnormal response of the mutant islets. In addition, stimulating islets from Foxa $2^{\text {loxP/loxP }}$; Ins.Cre mice with an amino acid mixture, which serves as a good secretagogue for glucagon but normally is not an effective stimulus for insulin, resulted in a dramatic and sustained secretion of insulin (Fig. 5c). Therefore, the persistent hyperinsulinemic hypoglycemia observed in the Foxa $2^{\text {loxP/loxP }}$; Ins.Cre mice in vivo is most likely the direct consequence of abnormal insulin secretion at lower blood glucose concentrations and an inappropriately high insulin secretory response to amino acids.

As we had also observed inappropriately low plasma glucagon levels, we hypothesized that glucagon secretion was defective in Foxa $2^{\operatorname{lox} P / \operatorname{lox} P}$; Ins.Cre mice. This was indeed the case as shown in Figure 5d. Addition of an amino-acid mixture as secretagogue for glucagon resulted in a robust release of glucagon from control pancreas but produced only a minimal response, if any, in mutant pancreas. In summary, these perfusion studies clearly showed that abnormal insulin and glucagon se- cretion can account for the physiological phenotype observed in Foxa $2^{\text {loxP//oxP }}$; Ins.Cre mutant mice.

\section{The ATP-sensitive $K^{+}$channel is a target of Foxa2 in $\beta$ cells}

A plausible explanation for the aberrant insulin secretion in Foxa2 ${ }^{\text {loxP } / 10 x P}$; Ins. Cre mutant mice is a dysregulation of the genes encoding components of the glucosesensing insulin secretory mechanism, namely, GLUT2, glucokinase, glutamate dehydrogenase (GDH), and the $\mathrm{K}_{\text {ATP }}$ channel. No significant changes were found in mRNA expression levels of GLUT2, glucokinase, or GDH (data not shown). However, mRNA levels for genes encoding both subunits of the $\mathrm{K}_{\mathrm{ATP}}$ channel, Kir6.2 and sulfonylurea receptor 1 (SUR1), were reduced by $73 \%$ and $81 \%$, respectively, in RNA isolated from pancreatic islets of Foxa2 $2^{\text {loxP } / 10 x P}$; Ins.Cre mice (Fig. 6), providing a molecular link between the deletion of the transcription factor Foxa2 in the $\beta$ cell and the hypoglycemic phenotype observed.

The importance of the $\mathrm{K}_{\mathrm{ATP}}$ channels in regulating 
Sund et al.

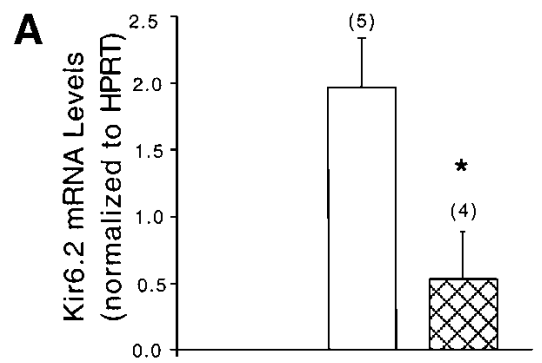

B

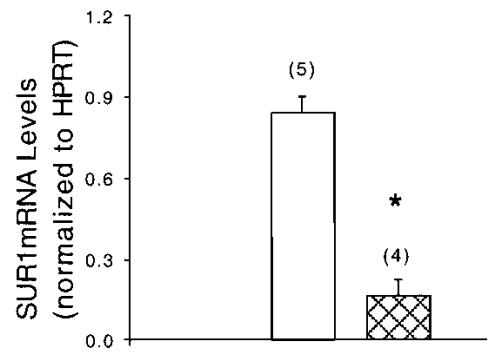

Figure 6. Foxa2 is required in $\beta$ cells for $\mathrm{K}_{\mathrm{ATP}}$-channel steadystate mRNA expression. Reverse-transcription PCR analysis of Kir6.2 $(a)$ and SUR1 $(b)$ mRNA levels in islet RNA from control (unfilled bars) and Foxa $2^{\operatorname{lox} P / \operatorname{lox} P}$; Ins.Cre (cross-hatched bars) mice, which were normalized to those of HPRT. Radioactive bands were quantified by phosphorimager analysis. Bars represent values \pm SEM, with number indicated in parenthesis. *, $P<0.05$; Foxa $2^{\text {lox } P / / \text { lox } P} ;$ Ins. Cre vs. control mice.

insulin secretion in vivo has been shown by the high frequency of mutations in the SUR1 and KIR6.2 genes in patients with hyperinsulinism (Thomas et al. 1995; Nestorowicz et al. 1996; Thomas et al. 1996; Dunne et al. 1997; Meissner et al. 1999) and by reports that neonatal mice overexpressing a dominant-negative inhibitor of $\mathrm{K}_{\mathrm{ATP}}$ channels or lacking $\mathrm{K}_{\mathrm{ATP}}$ channels altogether are at least transiently hypoglycemic (Miki et al. 1997, 1998; Seghers et al. 2000). Thus, the deficiency in $\mathrm{K}_{\mathrm{ATP}}$ channel expression in the Foxa $2^{\text {loxP/loxP }}$; Ins.Cre mutant mice is likely to contribute to the abnormal insulin secretion and hypoglycemia observed in these mice.

\section{Discussion}

In this study, we have used the Cre-loxP recombination system to uncover a dramatic function for Foxa2 in pancreatic $\beta$-cell differentiation and glucose homeostasis. The hyperinsulinemic state of the Foxa2 $2^{\text {loxP/loxP }}$; Ins.Cre mice results in peripheral glucose disposal and prevents mobilization of glycogen stores despite low blood glucose levels. The paradigm for glucose regulation of insulin secretion is that enhanced glucose metabolism results in a cascade of increased ATP production, closure of $\mathrm{K}_{\mathrm{ATP}}$ channels, membrane depolarization, activation of voltage-gated calcium channels, influx of calcium, and insulin granule exocytosis into the bloodstream (Dunne and Petersen 1991). The critical role of these glucoseinduced ionic events is highlighted by the genetic basis of familial hyperinsulinism (HI), a disease characterized by uncontrolled insulin secretion despite severe hypoglycemia (Dunne et al. 1999). Recently, mutations in the genes encoding four components of this pathway, namely, SUR1, Kir6.2, glucokinase, and GDH, have been identified in HI patients (Thomas et al. 1995, 1996; Nestorowicz et al. 1996; Glaser et al. 1998; Meissner et al. 1999; Stanley et al. 2000). These mutations are predicted to result in inactivation of the $\mathrm{K}_{\mathrm{ATP}}$ channel-dependent pathway directly or indirectly, linking glucosestimulated insulin secretion to the pathophysiology of HI. Thus, loss of $\mathrm{K}_{\mathrm{ATP}}$-channel activity results in partially glucose-blind $\beta$ cells, as seen in isolated islets from patients with HI (Kane et al. 1996, 1997; Dunne et al. 1997), very similar to the phenotype we describe here for mice that lack Foxa2 specifically in the $\beta$ cells of the pancreas.

We identified the $\mathrm{K}_{\mathrm{ATP}}$ channel as a novel target of Foxa2, as both Kir6.2 and SUR1 mRNA levels are reduced by $\sim 75 \%$ in islets of Foxa $2^{\text {loxp/loxP }}$; Ins.Cre mice. This reduced Kir6.2 and SUR1 expression in $\beta$ cells of our mutant mice most likely results in impaired $\mathrm{K}_{\mathrm{ATP}}$ channel activity and altered insulin secretion. This view is supported by recent studies using mouse models with reduced or absent $\mathrm{K}_{\mathrm{ATP}}$ channel activity. First, newborn mice with reduced $\mathrm{K}_{\mathrm{ATP}}$ channel activity are transiently hypoglycemic (Miki et al. 1997, 1998; Seghers et al. 2000). Second, islets from homozygous Sur $1^{-/-}$mice fail to suppress insulin output when blood glucose levels fall, similar to the Foxa2-deficient $\beta$ cells (Seghers et al. 2000). However, these newborn transgenic and mutant mice were not severely hypoglycemic and lived to adulthood, thus displaying a phenotype much milder than that of Foxa2 $2^{\text {loxP/IoxP }}$; Ins. Cre mice. The increased severity of the phenotype of Foxa $2^{\text {loxP/loxp }}$; Ins.Cre mice relative to $\mathrm{K}_{\mathrm{ATP}}$ channel-deficient mice may be caused by the simultaneous reduction of both subunits of the $\mathrm{K}_{\mathrm{ATP}}$ channel, the concurrent defect in glucagon secretion, or the contribution of an unidentified target of Foxa2. A $\mathrm{K}_{\mathrm{ATP}}$-independent pathway of insulin secretion has been invoked to explain the relatively mild phenotype of Sur $1^{-1-}$ mice (Seghers et al. 2000). Evidence for glucose action on insulin secretion beyond ionic events controlled by the $\mathrm{K}_{\mathrm{ATP}}$ channel has also been gained from pharmacological studies (Aizawa et al. 1998). However, the molecular basis of these nonionic insulinotropic glucose effects has not yet been delineated. Considering the very severe phenotype of the Foxa $2^{\text {loxP/loxP }}$; Ins. Cre mice compared with mice lacking only the $\mathrm{K}_{\mathrm{ATP}}$-channel, it is likely that these alternate nonionic pathways are perturbed in our mice as well, which provides a unique model for future investigations of these pathways.

The Foxa $2^{\text {loxP } / \text { loxp }}$; Ins.Cre model provides the first genetic evidence for in vivo coupling of $\alpha$-cell function to $\beta$ cells. This stems from our observation that circulating glucagon levels are also inappropriately low in our mutant mice, despite the $\beta$ cell-specific deletion of Foxa2. Several possibilities could explain how inactivation of Foxa2 in $\beta$ cells causes a defect in $\alpha$-cell function. First, there is prior evidence for paracrine regulation between $\beta$ 
and $\alpha$ cells. Insulin has been shown to inhibit $\alpha$-cell function (Maruyama et al. 1984, 1985), and chronic exposure of the $\alpha$ cells in our Foxa $2^{\operatorname{lox} P / / 0 x P}$; Ins. Cre mice to elevated levels of insulin may tonically inhibit glucagon secretion. Second, the noncell-autonomous requirement of Foxa 2 in $\beta$ cells for $\alpha$-cell function might be caused by perturbation of islet cell architecture in Foxa2 ${ }^{\text {loxP } / l o x P}$; Ins.Cre islets which could disrupt normal $\beta$ cell-to- $\beta$ cell and $\beta$ cell-to- $\alpha$ cell contacts.

In summary, our data show that Foxa2 is required in $\beta$ cells for maintaining proper circulating levels of insulin and glucagon and for glucose homeostasis. The Foxa $2^{\operatorname{lox} P / \operatorname{lox} P}$; Ins. Cre mice represent a novel and unique model that mimics many pathophysiological and molecular aspects of familial hyperinsulinism and as such will be useful for the evaluation of novel treatment regimens for this clinically relevant disorder.

\section{Materials and methods}

\section{Animals and genotype analysis}

Foxa $2^{\text {loxP/loxP }}$ mice were generated by homologous recombination using a Foxa2 gene-targeting vector with loxP sites flanking exon 3 as described previously (Sund et al. 2000). The derivation of the Foxa2 $2^{10 x P}$ and Ins.Cre transgenic line has been reported previously (Kulkarni et al. 1999; Postic et al. 1999; Sund et al. 2000). All mice were kept on a mixed outbred-CD1 background. Genotyping was performed by PCR analysis using genomic DNA isolated from the tail tip of fetal and newborn mice (Sund et al. 2000).

We focused our studies on P8 mice, because mutant mice at this age are still growing and are relatively healthy. In addition, all control littermates, including mice with heterozygous Foxa2 $\beta$ cells (Foxa $2^{l o x P /+}$; Ins.Cre), had similar values in all physiologic measurements examined (Fig. 2), and except where specified, the three genotypes were grouped together as control littermates. Preference in selecting controls was given to mice with one wild-type and one loxP allele of Foxa2 and no Ins.Cre transgene $\left(F_{0 x a 2^{l o x P /+}}\right)$, which is the closest genotype to wildtype mice in our mating scheme. Reducing the litter size such that the smaller mutant mice were able to better compete for nutrients allowed two rare Foxa2 $2^{\operatorname{lox} P / 10 x P}$; Ins.Cre mice to survive to P22, although they were severely runted and hypoglycemic (data not shown). In contrast, mice heterozygous for Foxa2 in $\beta$ cells $\left(\mathrm{Foxa}^{\text {loxP } /+}\right.$; Ins.Cre) were viable, had normal growth curves, and were fertile.

\section{Immunohistochemistry}

Tissues were fixed in $4 \%$ paraformaldehyde overnight at $4^{\circ} \mathrm{C}$, embedded in paraffin, cut to $6-\mu \mathrm{m}$ sections, and applied to Probe-on Plus slides (Fisher Scientific). Deparaffinized and rehydrated slides were subjected to microwave antigen retrieval by boiling for $6 \mathrm{~min}$ in a $10 \mathrm{mM}$ citric acid buffer (pH 6.0) and allowed to cool for $10 \mathrm{~min}$ at room temperature (RT). Slides were washed in PBS, then blocked with protein blocking reagent (Immunotech, no. 1481) for $20 \mathrm{~min}$ at RT. The primary antibodies were diluted in PBS containing $0.1 \%$ BSA and $0.2 \%$ Triton $\mathrm{X}-100$ (PBT) and incubated with the sections overnight at $4^{\circ} \mathrm{C}$. Slides were washed in PBS, then incubated with the appropriate secondary antibodies diluted in PBT for $2 \mathrm{~h}$ at RT. Slides were washed in PBS, mounted, and examined using confocal microscopy (Leica).

The following antibodies were used at the indicated dilutions for immunohistochemistry: rabbit anti-HNF-3 $\beta$ (a gift from Dr. T.M. Jessell, Columbia University, New York; 1:2000), guinea pig anti-insulin (Linco; 1:1000), guinea pig anti-glucagon (Linco; 1:200), rabbit anti-glucagon (Genosys; 1:200), rabbit anti-IAPP (amylin; Phoenix Pharmaceuticals; 1:1500), rabbit anti-somatostatin-28 (Genosys; 1:400), Cy3-conjugated donkey anti-rabbit IgG (Jackson Immunoresearch; 1:1500), FITC-conjugated donkey anti-rabbit IgG (Jackson; 1:50), Cy2-conjugated donkey antiguinea pig IgG (Jackson; 1:400), and rhodamine-conjugated goat anti-guinea pig IgG (Cappel; 1:50).

\section{Islet isolation and RNA analysis}

By combining two to five pancreata from P8 mice, islets were isolated using the standard collagenase procedure (Scharp et al. 1973). One hundred fifty to 200 islets were hand-picked under a light microscope. Total RNA from islets and pancreata from P8 mice was isolated by homogenization in TriReagent LS (Molecular Research Center) according to manufacturer instructions. Reverse-transcription PCR (RT-PCR) analysis was performed essentially as described (Wilson and Melton 1994; Duncan et al. 1997). To determine conditions for quantitative analysis, cDNA samples were serially diluted and each primer pair was tested for exponential amplification by modifying PCR cycle numbers and quantifying the signal using PhosphorImager (Molecular Dynamics) analysis (data not shown). PCR conditions used were 1 cycle of $93^{\circ} \mathrm{C}$ for $3 \mathrm{~min}, 20$ to 28 cycles (depending on primer pair) of $93^{\circ} \mathrm{C}$ for $45 \mathrm{sec}, 60^{\circ} \mathrm{C}$ for $45 \mathrm{sec}$, and $72^{\circ} \mathrm{C}$ for $2 \mathrm{~min}$, followed by 1 cycle of $72^{\circ} \mathrm{C}$ for $5 \mathrm{~min}$ in a buffer containing $1.5 \mathrm{mM} \mathrm{MgCl}_{2}$. The following forward and reverse primers were used for specific amplication (size in $\mathrm{bp}$ ): proInsulin 1, 5'-CCACCCAGGCTTTTGTCAAAC-3' and 5'AGCACTGATCCACAATGCCAC-3' (218); proglucagon, 5'GCACATTCACCAGCGACTACA-3' and 5'-CTGGTGGCAA GATTGTCCAGA-3' (330); glucokinase, 5'-GCAGGGGATC CAAATAGGGAA-3' and 5'-CTTGCTTCTCTTCCCGGATCA3' (375); GDH, 5' -GCCAAGGTCTATGAAGGAAGC-3' and 5'GACACTGTTACTCCTCCAGCA-3' (223); SUR1, 5'-GCCCA CAGAGGTACATCTTCT-3' and 5'-CAGAGTCGCTGATAG TTGGTG-3' (226); Kir6.2, 5'-GCAGAAACCCTCATCTTCA GC-3' and 5'-CAGAGTGGTGTGGGCACTTTA-3' (500); HP RT, 5'-GGCCATCTGCCTAGTAAAGCT-3' and 5'-GCTGGC CTATAGGCTCATAGT-3'; $\alpha$-tubulin, $5^{\prime}$-GTGTCTTCCAT CACTGCTTCC-3' and 5'-GCTCAAAGCAGGCATTGGTGA-3'.

\section{Analytical procedures}

Blood glucose values were determined from whole venous blood using an automatic glucose monitor (Glucometer Elite, Bayer). To prepare plasma, mice were killed by decapitation on $\mathrm{P} 8$, and whole venous blood was instantly mixed with $5 \%(\mathrm{v} / \mathrm{v})$ of TEL solution (trasylol 10,000 KIU/mL, $60 \mathrm{mM}$ EDTA, $0.5 \mathrm{mg} / \mathrm{mL}$ leupeptin). After centrifugation, the resulting plasma was stored at $-80^{\circ} \mathrm{C}$ until assayed. Plasma insulin was measured by ELISA (Mercodia Ultrasensitive Rat Insulin ELISA, American Laboratory Products). Plasma glucagon was determined using RIA (University of Pennsylvania Diabetes Center.) Plasma nonesterified fatty acid levels were determined using a colorimetric enzyme assay (NEFA C, Wako Chemicals, Germany). Pancreatic insulin and glucagon content was assessed by RIA (University of Pennsylvania Diabetes Center) in acid-ethanol extracts of 
whole pancreas. Hepatic glycogen content was determined as described previously (Postic et al. 1999).

\section{Quantitative islet cell area measurement}

The pancreata from five P8 Foxa $2^{\text {loxP/loxP }}$; Ins.Cre mice and five control littermates were fixed in paraformaldehyde and processed for immunohistochemistry as described above. To obtain the largest surface area for analysis, the pancreata were laid flat during the paraffin-embedding process. Sections $(5 \mu \mathrm{m})$ through the entire pancreas were taken, and every fifth section was stained with hematoxylin and eosin. The section with the largest tissue surface area was selected for analysis. Sections were double-stained with guinea pig anti-insulin and rabbit anti-glucagon antibodies using immunofluorescence as described above, except images were analyzed using a Nikon MicrophotFX fluorescent microscope. The area covered by cells stained by each antibody was measured using IP Lab Spectrum software and expressed as a percentage of the total pancreatic area. This study was performed blinded to the genotypes of the animals.

\section{Pancreas perifusion}

Dissected pancreata from two P8 mice were immediately minced into fine pieces and placed into a perifusion chamber (Millipore). The perifusion apparatus consisted of a computercontrolled fast-performance HPLC system (Waters 625 LC System) that allowed programmable rates of flow and glucose concentration in the perifusate, a water bath $\left(37^{\circ} \mathrm{C}\right)$, and a fraction collector (Waters Division of Millipore). The perifusate was Krebs buffer ( $\mathrm{pH} 7.4$ ) containing $2.2 \mathrm{mM} \mathrm{Ca}^{2+}, 0.25 \%$ bovine serum albumin and was equilibrated with $95 \% \mathrm{O}_{2}$ and $5 \% \mathrm{CO}_{2}$, plus additional secretagogues. The amino acid mixture contained physiological concentrations of 19 amino acids (15 mM) plus 2 mM glutamine (Sigma, G-7029). At the beginning of each experiment, perfusate without any secretagogues was perfused for $30 \mathrm{~min}$ to wash out any released hormones and to reach baseline hormone secretion values.

\section{Statistical procedures}

All values unless otherwise indicated are expressed as mean \pm SEM. Statistical analyses were carried out using a two-tailed Student's unpaired $t$ test, and the null hypothesis was rejected at the 0.05 level.

\section{Acknowledgments}

The authors are grateful to Drs. M. Birnbaum, J. Blendy, C. Lee, L. Greenbaum, and C. Stanley for critical reading of the manuscript; Dr. T. Jessell for providing immunoreagents; and Dr. H. Collins for assistance in plasma analysis and radioimmunoassays. Our studies were facilitated by the University of Pennsylvania Diabetes Center (P30 DK19525) and the Penn Center for Molecular Studies in Digestive and Liver Disease (P30 DK50306). This work was supported by the NIDDK (RO1 DK55342 to KHK), the Association pour la Recherche sur le Cancer, the Institute National de la Santé et de la Recherche Médicale, the Centre National de la Recherche Scientifique, and the Centre Hospitalier Universitaire Régional to SLA. NJS was supported through a National Institutes of Health predoctoral training grant (5-T32-GM08216).

The publication costs of this article were defrayed in part by payment of page charges. This article must therefore be hereby marked "advertisement" in accordance with 18 USC section 1734 solely to indicate this fact.

\section{References}

Aizawa, T., Komatsu, M., Asanuma, N., Sato, Y., and Sharp, G.W. 1998. Glucose action "beyond ionic events" in the pancreatic $\beta$ cell. Trends Pharmacol. Sci. 19: 496-499.

Alpert, S., Hanahan, D., and Teitelman, G. 1988. Hybrid insulin genes reveal a developmental lineage for pancreatic endocrine cells and imply a relationship with neurons. Cell 53: 295-308.

Ang, S.L. and Rossant, J. 1994. HNF-3 beta is essential for node and notochord formation in mouse development. Cell 78: 561-574.

Ang, S.L., Wierda, A., Wong, D., Stevens, K.A., Cascio, S., Rossant, J., and Zaret, K.S. 1993. The formation and maintenance of the definitive endoderm lineage in the mouse: Involvement of HNF3/forkhead proteins. Development 119: 1301-1315.

Dufort, D., Schwartz, L., Harpal, K., and Rossant, J. 1998. The transcription factor HNF3 $\beta$ is required in visceral endoderm for normal primitive streak morphogenesis. Development 125: 3015-3025.

Duncan, S.A., Nagy, A., and Chan, W. 1997. Murine gastrulation requires HNF-4 regulated gene expression in the visceral endoderm: Tetraploid rescue of $\mathrm{Hnf}-4^{-/-}$embryos. Development 124: 279-287.

Dunne, M.J., Cosgrove, K.E., Shepherd, R.M., and Ammala, C. 1999. Potassium channels, sulphonylurea receptors and control of insulin release. Trends Endocrinol. Metab. 10: 146152.

Dunne, M.J., Kane, C., Shepherd, R.M., Sanchez, J.A., James, R.F., Johnson, P.R., Aynsley-Green, A., Lu, S., Clement, J.P.t., Lindley, K.J., et al. 1997. Familial persistent hyperinsulinemic hypoglycemia of infancy and mutations in the sulfonylurea receptor. N. Engl. J. Med. 336: 703-706.

Dunne, M.J. and Petersen, O.H. 1991. Potassium selective ion channels in insulin-secreting cells: Physiology, pharmacology and their role in stimulus-secretion coupling. Biochim. Biophys. Acta 1071: 67-82.

Glaser, B., Kesavan, P., Heyman, M., Davis, E., Cuesta, A., Buchs, A., Stanley, C.A., Thornton, P.S., Permutt, M.A., Matschinsky, F.M., et al. 1998. Familial hyperinsulinism caused by an activating glucokinase mutation. N. Engl. J. Med. 338: 226-230.

Kaestner, K.H., Katz, J., Liu, Y., Drucker, D.J., and Schütz, G. 1999. Inactivation of the winged helix transcription factor HNF3alpha affects glucose homeostasis and islet glucagon gene expression in vivo. Genes \& Dev. 13: 495-504.

Kaestner, K.H., Knöchel, W., and Martinez, D.E. 2000. Unified nomenclature for the winged helix/forkhead transcription factors. Genes \& Dev. 14: 142-146.

Kane, C., Lindley, K.J., Johnson, P.R., James, R.F., Milla, P.J., Aynsley-Green, A., and Dunne, M.J. 1997. Therapy for persistent hyperinsulinemic hypoglycemia of infancy: Understanding the responsiveness of $\beta$ cells to diazoxide and somatostatin. J. Clin. Invest. 100: 1888-1893.

Kane, C., Shepherd, R.M., Squires, P.E., Johnson, P.R., James, R.F., Milla, P.J., Aynsley-Green, A., Lindley, K.J., and Dunne, M.J. 1996. Loss of functional KATP channels in pancreatic $\beta$-cells causes persistent hyperinsulinemic hypoglycemia of infancy. Nat. Med. 2: 1344-1347.

Kim, S.K., Hebrok, M., and Melton, D.A. 1997. Notochord to endoderm signaling is required for pancreas development. Development 124: 4243-4252.

Kulkarni, R.N., Bruning, J.C., Winnay, J.N., Postic, C., Magnuson, M.A., and Kahn, C.R. 1999. Tissue-specific knockout of the insulin receptor in pancreatic $\beta$ cells creates an insulin 
secretory defect similar to that in type 2 diabetes. Cell 96: 329-339.

Maruyama, H., Hisatomi, A., Orci, L., Grodsky, G.M., and Unger, R.H. 1984. Insulin within islets is a physiologic glucagon release inhibitor. J. Clin. Invest. 74: 2296-2299.

Maruyama, H., Tominaga, M., Bolli, G., Orci, L., and Unger, R.H. 1985. The $\alpha$ cell response to glucose change during perfusion of anti-insulin serum in pancreas isolated from normal rats. Diabetologia 28: 836-840.

Meissner, T., Beinbrech, B., and Mayatepek, E. 1999. Congenital hyperinsulinism: Molecular basis of a heterogeneous disease. Hum. Mutat. 13: 351-361.

Miki, T., Nagashima, K., Tashiro, F., Kotake, K., Yoshitomi, H., Tamamoto, A., Gonoi, T., Iwanaga, T., Miyazaki, J., and Seino, S. 1998. Defective insulin secretion and enhanced insulin action in KATP channel-deficient mice. Proc. Natl. Acad. Sci. 95: 10402-10406.

Miki, T., Tashiro, F., Iwanaga, T., Nagashima, K,. Yoshitomi, H., Aihara, H., Nitta, Y., Gonoi, T., Inagaki, N., Miyazaki, J., et al. 1997. Abnormalities of pancreatic islets by targeted expression of a dominant-negative KATP channel. Proc. Natl. Acad. Sci. 94: 11969-11973.

Monaghan, A.P., Kaestner, K.H., Grau, E., and Schütz, G. 1993. Postimplantation expression patterns indicate a role for the mouse forkhead/HNF- $3 \alpha, \beta$ and $\gamma$ genes in determination of the definitive endoderm, chordamesoderm and neuroectoderm. Development 119: 567-578.

Nestorowicz, A., Wilson, B.A., Schoor, K.P., Inoue, H., Glaser, B., Landau, H., Stanley, C.A., Thornton, P.S., Clement, J.P.t., Bryan, J., et al. 1996. Mutations in the sulonylurea receptor gene are associated with familial hyperinsulinism in Ashkenazi Jews. Hum. Mol. Genet. 5: 1813-1822.

Postic, C., Shiota, M., Niswender, K.D., Jetton, T.L., Chen, Y., Moates, J.M., Shelton, K.D., Lindner, J., Cherrington, A.D., and Magnuson, M.A. 1999. Dual roles for glucokinase in glucose homeostasis as determined by liver and pancreatic $\beta$ cell-specific gene knock-outs using Cre recombinase. J. Biol. Chem. 274: 305-315.

Sasaki, H. and Hogan, B.L. 1993. Differential expression of multiple fork head related genes during gastrulation and axial pattern formation in the mouse embryo. Development 118: 47-59.

Scharp, D.W., Kemp, C.B., Knight, M.J., Ballinger, W.F., and Lacy, P.E. 1973. The use of ficoll in the preparation of viable islets of langerhans from the rat pancreas. Transplantation 16: 686-689.

Seghers, V., Nakazaki, M., DeMayo, F., Aguilar-Bryan, L., and Bryan, J. 2000. Surl knockout mice: A model for K(ATP) channel-independent regulation of insulin secretion. J. Biol. Chem. 275: 9270-9277.

Shih, D.Q., Navas, M.A., Kuwajima, S., Duncan, S.A., and M. Stoffel, M. 1999. Impaired glucose homeostasis and neonatal mortality in hepatocyte nuclear factor $3 \alpha$-deficient mice. Proc. Natl. Acad. Sci. 96: 10152-10157.

Slack, J.M. 1995. Developmental biology of the pancreas. Development 121: 1569-1580.

Sosa-Pineda, B., Chowdhury, K., Torres, M., Oliver, G., and Gruss, P. 1997. The Pax4 gene is essential for differentiation of insulin-producing beta cells in the mammalian pancreas. Nature 386: 399-402.

St-Onge, L., Sosa-Pineda, B., Chowdhury, K., A. Mansouri, B., and Gruss, P. 1997. Pax6 is required for differentiation of glucagon-producing alpha-cells in mouse pancreas. Nature 387: 406-409.

St-Onge, L., Wehr, R., and Gruss, P. 1999. Pancreas development and diabetes. Curr. Opin. Genet. Dev. 9: 295-300.
Stanley, C.A., Fang, J., Kutyna, K., Hsu, B.Y., Ming, J.E., Glaser, B., and Poncz, M. 2000. Molecular basis and characterization of the hyperinsulinism/hyperammonemia syndrome: predominance of mutations in exons 11 and 12 of the glutamate dehydrogenase gene. HI/HA Contributing Investigators. Diabetes 49: 667-673.

Sund, N.J., Ang, S.L., Sackett, S.D., Shen, W., Daigle, N., Magnuson, M.A., and Kaestner, K.H. 2000. Hepatocyte nuclear factor $3 \beta$ (Foxa2) is dispensable for maintaining the differentiated state of the adult hepatocyte. Mol. Cell Biol. 20: 51755183.

Thomas, P., Ye, Y., and Lightner, E. 1996. Mutation of the pancreatic islet inward rectifier Kir6.2 also leads to familial persistent hyperinsulinemic hypoglycemia of infancy. Hum. Mol. Genet. 5: 1809-1812.

Thomas, P.M., Cote, G.J., Wohllk, N., Haddad, B., Mathew, P.M., Rabl, W., Aguilar-Bryan, L., Gagel, R.F., and Bryan, J. 1995. Mutations in the sulfonylurea receptor gene in familial persistent hyperinsulinemic hypoglycemia of infancy. Science 268: 426-429.

Weinstein, D.C., Ruiz i Altaba, A., Chen, W.S., Hoodless, P., Prezioso, V.R., Jessell, T.M., and Darnell Jr, J.E. 1994. The winged-helix transcription factor HNF-3 $\beta$ is required for notochord development in the mouse embryo. Cell 78: 575588.

Wilson, P.A. and Melton, D.A. 1994. Mesodermal patterning by an inducer gradient depends on secondary cell-cell communication. Curr. Biol. 4: 676-686. 


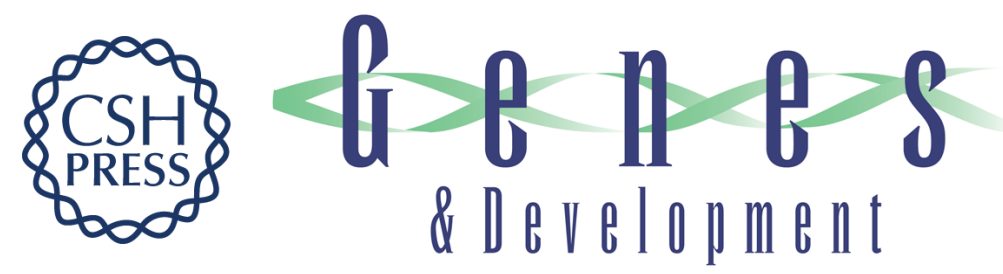

\section{Tissue-specific deletion of Foxa2 in pancreatic $\beta$ cells results in hyperinsulinemic hypoglycemia}

Newman J. Sund, Marko Z. Vatamaniuk, Melissa Casey, et al.

Genes Dev. 2001, 15:

Access the most recent version at doi:10.1101/gad.901601

References This article cites 37 articles, 17 of which can be accessed free at: http://genesdev.cshlp.org/content/15/13/1706.full.html\#ref-list-1

License

Email Alerting

Receive free email alerts when new articles cite this article - sign up in the box at the top Service right corner of the article or click here.

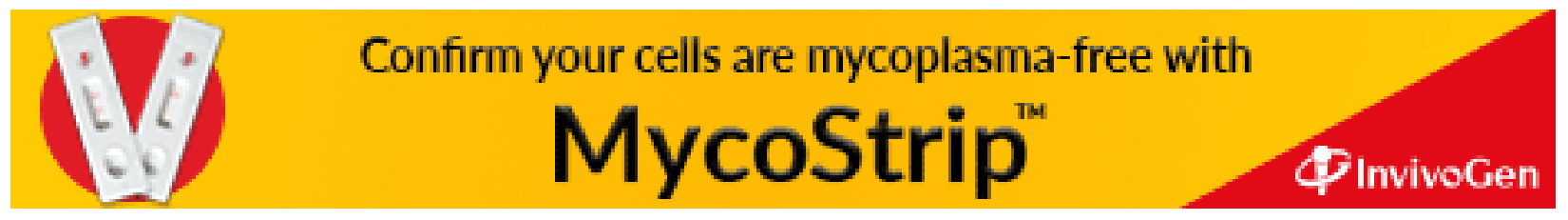

